\title{
Diferentes desinfetantes sobre a contaminação e desempenho da incubação de ovos de avestruz
}

\author{
Nadia Nobrega Valdo, Sheila Merlo Garcia, Lilian Francisco Arantes de Souza \\ Universidade do Oeste Paulista - UNOESTE, Presidente Prudente, SP. E-mail: nadianobrega@outlook.com
}

\begin{abstract}
Resumo
A partir do momento da postura os ovos entram em contato com microrganismos que se aderem à casca e a desinfecção é o processo que reduz a contaminação evitando que penetrem na casca e invadam o conteúdo interno do ovo, entretanto, diferentes princípios ativos podem resultar em efeitos diversos. Objetivou-se avaliar a eficiência de diferentes princípios ativos na desinfecção de ovos de avestruz sobre a contaminação e os índices produtivos da incubação. Foram utilizados 16 ovos distribuídos em dois princípios ativos desinfetantes (amônia quaternária e formaldeído) em Delineamento Inteiramente Casualizado com 8 repetições. A contaminação da casca dos ovos foi avaliada por meio de análise microbiológica na superfície da casca dos ovos após desinfecção. Os índices produtivos da incubação foram avaliados por meio de índice de perda de peso do ovo (\%), taxa de mortalidade (\%), embriodiagnóstico (\%) e eclodibilidade (\%). Não houve diferença significativa $(p>0,05)$ entre os princípios ativos utilizados quanto à capacidade de desinfecção e índices produtivos da incubação. Conclui-se que ambos os princípios ativos são eficientes na desinfecção dos ovos, garantindo o controle da contaminação na superfície da casca dos ovos durante os processos de armazenagem e incubação, além de não afetar os parâmetros da incubação.

Palavras-chave: desinfecção; eclodibilidade; Struthiocamelus.
\end{abstract}

\section{Diferent disinfectantes on the contamination and incubation performace of ostrich eggs}

\begin{abstract}
From the moment of laying, eggs come into contact with microorganisms that adhere to the shell and disinfection is the process that reduces contamination by preventing them from penetrating the shell and invading the egg's internal content, however, different active principles can result in effects several. The objective was to evaluate the efficiency of different active principles in the disinfection of ostrich eggs on contamination and the productive indexes of incubation. 16 eggs were used, distributed in two disinfectant active ingredients (quaternary ammonia and formaldehyde) in a completely randomized design with 8 replications. Contamination of the eggshell was evaluated by microbiological analysis on the surface of the eggshell after disinfection. The productive indexes of the incubation were evaluated by means of the index of weight loss of the egg (\%), mortality rate (\%), embryology (\%) and hatchability (\%). There was no significant difference $(p>0.05)$ between the active ingredients used in terms of disinfection capacity and productive indexes of incubation. It is concluded that both active ingredients are efficient in the disinfection of eggs, ensuring the control of contamination on the surface of the egg shell during the storage and incubation processes, in addition to not affecting the parameters of the incubation.
\end{abstract}

Keywords: disinfection; hatchability; Struthiocamelus.

\section{Introdução}

A criação mundial com finalidade
comercial de avestruzes tem crescido
significativamente, acarretando em maior
demanda por conhecimentos e habilidades no

setor (OLIVEIRA et al., 2014). Entretanto, o início da atividade no Brasil foi marcado por perdas consideráveis de ovos e filhotes, devido à falta de definição dos parâmetros de incubação (VAN SCHALKWYK et al., 1996). Dessa forma, para 
elevar índices como eclodibilidade, alguns padrões da incubação devem ser observados, tais como a correta coleta e higienização dos ovos, qualidade da casca, o manejo do incubatório, as condições de incubação e o funcionamento adequado dos equipamentos (BRAMWELL, 2002).

No momento da postura os ovos adquirem uma quantidade de microrganismos que se aderem à casca. Em razão disso, torna-se necessária a desinfecção dos ovos incubáveis, uma vez que à maioria dos problemas resultantes da invasão de microrganismos deve-se a falhas na sanitização dos ovos (SCOTT; SWETNAM, 1993).

A desinfecção dos ovos incubavéis momentos após a postura é uma das diversas práticas relacionadas ao manejo e a sanidade, sendo que essa atividade deve ser realizada de maneira correta e com desinfetantes apropriados. A realização inapropriada desse processo, indubitavelmente resulta em perdas significativas na eclodibilidade. Inúmeros métodos de desinfecção e princípios ativos têm sido aplicados com relativa eficiência, todavia, várias dúvidas têm surgido com o decorrer do tempo a respeito da eficiência dos processos e desinfetantes utilizados, em relação à toxicidade tanto para os embriões como para as pessoas que atuam nesse processo produtivo, relação custo-benefício, além do grande número de produtos oferecidos no mercado (CONY, 2007).

Os métodos mais utilizados para desinfecção dos ovos incubáveis são a pulverização, imersão e fumigação dos ovos, uma vez que os princípios ativos mais utilizados são os compostos quaternários de amônia e o formaldeído. Devido aos poucos estudos a respeito dos fatores físicos e funcionais dos ovos de avestruzes e suas relações com as incubações artificiais praticadas faz-se importante e oportuno realizar pesquisas nessa área.

Dessa forma, objetivou-se com esse trabalho, avaliar a eficiência de diferentes desinfetantes na desinfecção de ovos de avestruz sobre a capacidade de redução microbiana na superfície da casca, eclodibilidade dos ovos férteis, contaminação dos ovos incubados e mortalidade embrionária.

\section{Metodologia}

O experimento foi conduzido no setor de incubação do Centro Zootécnico da Universidade do Oeste Paulista (UNOESTE) em Presidente Prudente, São Paulo.
Para a realização do experimento, foi utilizada uma incubadora Premium Ecológica, modelo IP 30 horizontal com capacidade para 18 ovos, equipada com termômetro de álcool e termômetro bulbo seco e úmido.

Realizou-se a incubação de 16 ovos no total (n), os quais foram separados em dois grupos experimentais inteiramente ao acaso com 8 ovos (repetições) cada um. Para higienização dos ovos, foram utilizados dois tratamentos com diferentes desinfetantes: T1- amônia quaternária e T2-formaldeído nas concentrações de 400ppm e $1 \%$, respectivamente. Os ovos coletados foram oriundos das avestruzes reprodutoras do setor de estrutiocultura da UNOESTE. Os ovos foram coletados e armazenados durante 7 dias em temperatura inferior a $18^{\circ} \mathrm{C}$.

A coleta dos ovos foi realizada duas vezes ao dia, sempre no mesmo período entre às $07 \mathrm{~h} 00$ e $08 \mathrm{~h} 00$ da manhã e $18 \mathrm{~h} 40 \mathrm{~min}$ e $19 \mathrm{~h} 30 \mathrm{~min}$ da noite, garantindo que os ovos não permaneceram no ninho por mais de 4 horas, sendo que os ovos postos fora desse período ou que passaram mais do que 4 horas no ninho foram excluídos. Os ovos foram coletados com a utilização de luvas e saquinhos individuais e descartáveis.

Após a coleta nos piquetes os mesmos foram transportados até o setor de incubação, onde passaram por um processo de seleção em que ovos sujos, com presença de umidade, casca irregular e com pouca presença de proteína protetora foram descartados. Dessa maneira, os ovos selecionados para incubação passaram por desinfecção realizada pelo método de pulverização, assim o produto foi borrifado sobre a casca dos ovos, permanecendo por alguns segundos e logo removido com algodão, em seguida foram identificados de acordo com o piquete, numerados, pesados, medidos e passados por identificação da câmara de ar. Ao final os ovos foram estocados com inclinação de 45 e e câmara de ar voltada para cima. Durante o período de estocagem foi realizada a viragem manual uma vez ao dia.

Os dois grupos foram mantidos na incubadora até o $38^{\circ}$ dia de incubação, em temperatura e umidade média de $36,5^{\circ} \mathrm{C}$ e $48 \%$ respectivamente. Ao final, os ovos foram transferidos para o nascedouro, onde permaneceram até o $42 \circ$ dia com temperatura média de $36^{\circ} \mathrm{C}$, sendo $0,5^{\circ} \mathrm{C}$ menor que a temperatura de incubação, pois nessa fase o filhote já produz seu próprio calor e o nascedouro apresentava lotação máxima. Para auxiliar na 
manutenção da temperatura foram adicionadas duas lâmpadas monocromáticas amarelas de 40 watts. A umidade do ar no nascedouro foi mantida entre 60 e $70 \%$. A viragem dos ovos na incubadora foi realizada a cada 4 horas, com inclinação de $60^{\circ}$ até o $38^{\circ}$ dia de incubação.

Durante todo o processo de incubação, os ovos foram supervisionados uma vez ao dia e passaram por processo de pesagem, ovoscopia e demarcação da câmara de ar nas ovoscopias, as quais foram realizadas nos dias 14, 21 e 38 após o início da incubação. Do 39o ao 42ㅇ dia (data provável do nascimento) os ovos passaram por ovoscopia uma vez ao dia de modo a detectar possível perfuração da câmara de ar.

A quantificação das unidades formadoras de colônias (UFC) para a avaliação da eficiência dos dois tipos de desinfetantes foi executada no Laboratório de Microbiologia do Hospital Veterinário (HV) da UNOESTE por meio de análise microbiológica em cultura de anaerobiose realizada a partir de amostras coletadas da superfície das cascas dos ovos incubados, utilizando a técnica de esfregaço com a utilização de swabs e de placas estéreis e descartáveis $(5 \times 5 \mathrm{~cm})$. Foi coletada uma amostra de cada ovo que já estava incubado. $O$ desempenho dos desinfetantes em relação à diminuição do índice de contaminação e consequentemente melhorias em relação à taxa de nascimento foi realizado por meio do índice de eclodibilidade que foi calculado através da relação entre o número de ovos eclodidos e o número de ovos férteis incubados.

O embriodiagnóstico foi realizado nos ovos não eclodidos, os quais foram classificados em contaminados (coloração e odor característicos), claros ou inférteis, contaminados e inférteis, mortalidade embrionária inicial (1 a 14 dias de incubação), intermediária (15 a 28 dias de incubação) e tardia (29 a 42 dias de incubação) (CARRER et al., 2004).

Os dados referentes aos pesos dos ovos e perda de umidade foram analisados por meio do teste $\mathrm{t}$ de Student. Os dados referentes à eclodibilidade, embriodiagnóstico e níveis de UFC foram analisados por meio do teste exato de Fisher e G. As análises foram realizadas no programa BioEstat 5.3 utilizando nível de significância de $5 \%$.

\section{Resultados e Discussão}

$\mathrm{Na}$ análise microbiológica da superfície da casca dos ovos não foi encontrado presença de Mesófilos totais, coliformes totais, Pseudomona ssp e Aspergillu ssp. para nenhum dos tratamentos testados (Tabela 1), evidenciando o manejo correto no momento da coleta e desinfecção dos ovos assim como a boa ação dos princípios ativos utilizados.

Tabela 1. Análise microbiológica da casca dos ovos submetidos à desinfecção por diferentes princípios ativos.

\begin{tabular}{lcc}
\hline \multirow{2}{*}{ UFC/g* } & \multicolumn{2}{c}{ Desinfetante } \\
\cline { 2 - 3 } & Formaldeído & $\begin{array}{c}\text { Amônia } \\
\text { Quaternária }\end{array}$ \\
\hline Mesófilos totais** & 0,0 & 0,0 \\
\hline Bolores e & 0,0 & 0,0 \\
leveduras** & & \\
Coliformes totais** & 0,0 & 0,0 \\
Pseudomonas spp.** & 0,0 & 0,0 \\
Aspergillus spp.** & 0,0 & 0,0 \\
\hline
\end{tabular}

*UFC/g=Unidades formadoras de colônias

** valor de $\mathrm{p}$ (teste exato de Fisher) $>0,05$

Brake e Sheldon (1990) avaliaram a contagem microbiológica da casca dos ovos pulverizados com amônia quaternária em relação ao grupo controle e verificaram que a redução bacteriana foi de $98 \%$ após a desinfecção.

Em estudo realizado por Stringhini (2008), que comparou resultados das contagens de mesófilos nas cascas dos ovos de galinha lavados com hipoclorito de cálcio e com clorexidina, verificou menor contagem de bactérias nos ovos da sala de classificação da granja, desinfectados com clorhexidina, constatando que esse produto foi um desinfetante mais eficaz que o hipoclorito de cálcio.

Lacerda (2011), avaliou a qualidade físicoquímica e microbiológica de ovos de codorna e observou que o mecanismo de desinfecção por meio da pulverização com solução de cloro a 5 ppm, diminuiu o volume microbiano em ovos contaminados propositalmente com Salmonella Typhimurium.

Assim, os resultados obtidos na análise microbiológica mostram que as desinfecções da casca dos ovos realizadas tanto com amônia quaternária como com formaldeído após a postura foram eficientes no controle do desenvolvimento contínuo e exponencial dos microrganismos.

Não houve efeito significativo $(p>0,05) d a$ higienização realizada com amônia quaternária ou com formaldeído sobre os índices de peso 
médio dos ovos nos dias 0 ou 38 e perda de peso dos ovos durante a incubação (Tabela 2).

Tabela 2. Peso médio e desvio padrão dos ovos no dia da incubação $(\mathrm{PO}, \mathrm{g})$, peso médio dos ovos aos 38 dias de incubação $(P 38, g)$ e perda de peso dos ovos durante a incubação (Perda, \%) com diferentes desinfetantes.

\begin{tabular}{lccc}
\hline \multicolumn{3}{c}{ Desinfetante } & \\
\cline { 1 - 3 } & Formaldeído & $\begin{array}{c}\text { Amônia } \\
\text { Quaternária }\end{array}$ & \\
\hline P0 & $1434,8 \pm 98,9$ & $1417,8 \pm 178,8$ & 0,8174 \\
P38 & $1225,3 \pm 71,0$ & $1226,0 \pm 158,0$ & 0,9904 \\
Perda & $14,3 \pm 1,8$ & $13,6 \pm 2,2$ & 0,4922 \\
\hline
\end{tabular}

Se a capacidade de redução microbiana dos desinfetantes não for efetiva, os mesmos podem causar alterações sobre a perda de peso dos ovos, devido à penetração de bactérias e outros microrganismos no interior dos ovos, acarretando em produção de gases e consequentemente influência sobre a perda de umidade durante a incubação. Em estudo realizado por Lacerda et al. (2016), utilizando ovos de codorna contaminados com Salmonella entérica e Typhimurium e mantidos sob refrigeração não mostraram diferença em relação aos não contaminados; entretanto, quando não submetidos a refrigeração, o peso dos ovos do grupo contaminado foi inferior ao grupo sem contaminação.

Lacerda et al. (2016) afirma que ovos contaminados apresentam menor peso quando desinfetados. Sendo que a sanitização beneficia a perda de peso de ovos contaminados. A perda de peso dos ovos está relacionada com a quantidade e tamanho dos poros, a espessura ou resistência da casca e com as condições ambientais, assim, elevada concentração de poros ou poros com diâmetros grandes, promovem efeitos desfavoráveis devido à maior possibilidade de desidratação. A diminuição de peso dos ovos pode ser determinada por meio da provável perda de sulfeto de hidrogênio, amônia e nitrogênio que são produtos da degradação química de seus constituintes orgânicos.

Em ambos os tratamentos, os ovos apresentaram peso médio e perda de peso estatisticamente iguais $(14,25$ com formaldeído e 13,56 com amônia quaternária) e semelhantes aos encontrados na literatura, estando dentro dos parâmetros considerados ideais. De acordo com Nahm (2001), a desidratação dos ovos pode variar de $12 \%$ a $18 \%$. Em estudos realizados no Brasil, Carrer e Kornfeld (2001), encontraram valores para a perda de água dos ovos de avestruzes entre 14 e $16 \%$. Sendo assim, esses resultados refletem o adequado manejo da umidade durante a incubação.

A Tabela 3 mostra os resultados referentes à eclodibilidade e embriodiagnóstico (Figuras 1, 2 e 3). Em relação aos parâmetros de ovos inférteis, contaminados e contaminados inférteis, os valores observados foram numericamente iguais nos dois tratamentos. Foi encontrado um ovo infértil e um ovo infértil e contaminado em cada tratamento, ovos somente contaminados não foram detectados em nenhum dos tratamentos. Esses resultados podem estar relacionados ao tempo de permanência dos ovos no ninho e não na desinfecção, já que a análise microbiológica não detectou microrganismos na superfície, desse modo, a penetração de microrganismos pode ter ocorrido antes da desinfeção.

Os resultados obtidos mostram que não houve diferença significativa $(p>0,05)$ entre os desinfetantes utilizados sobre a eclodibilidade ou embriodiagnóstico, evidenciando que os produtos utilizados não diferem em relação aos parâmetros do desempenho da incubação. Esses resultados assemelham-se com os obtidos por Cony (2007), que ao comparar os percentuais de ovos de galinha desinfetados com formaldeído e amônia quaternária não evidenciaram diferença estatística entre estes tratamentos.

Tabela 3. Valores percentuais (\%) e absolutos da eclodibilidade e embriodiagnóstico (mortalidade inicial, intermediária e tardia) com diferentes desinfetantes.

\begin{tabular}{lccc}
\hline \multirow{2}{*}{ Índices produtivos } & \multicolumn{2}{c}{ Desinfetante } & \multirow{2}{*}{ Valor de $\mathbf{p}$} \\
\cline { 2 - 3 } & Formaldeído & Amônia Quaternária & \\
\hline Eclodibilidade & $33,33(2)$ & $0,00(0)$ & 0,4667 \\
\hline Mortalidade inicial & $16,67(1)$ & $50,00(3)$ & \multirow{2}{*}{0,5160} \\
Mortalidade intermediária & $16,67(1)$ & $33,33(2)$ & \\
Mortalidade tardia & $33,33(2)$ & $16,67(1)$ & \\
\hline
\end{tabular}


Figura 1. Mortalidade inicial

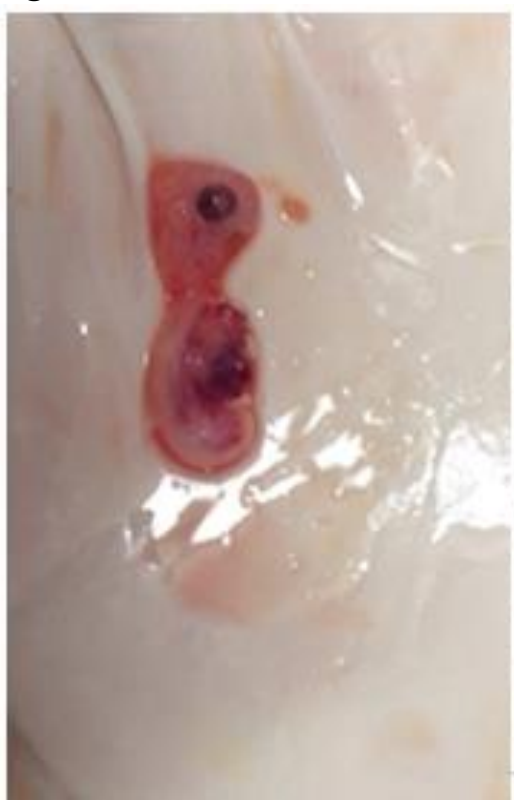

Fonte: arquivo pessoal

O método de desinfeção foi eficiente, entretanto, as baixas taxas de eclodibilidade e alta mortalidade embrionária refletem outros problemas associados ao manejo da incubação. Considerando-se apenas as mortes, sem distinção de tratamentos, observou-se que os maiores índices foram no terço inicial e no terço final do desenvolvimento embrionário. Segundo Carrer et al. (2004) essas ocorrências estão relacionadas a aspectos ligados ao manejo de incubação e/ou genéticos, afirmando que essas ocorrências não são sinais de problemas nutricionais. Gonzalez et al. (1999) diz que a maior taxa de mortalidade embrionária ocorre no terço final e pode ser influenciada pelas características da casca dos ovos. Dessa forma, Deeming (1995), observou $56,25 \%$ de mortalidade em ovos incubados pelo menos 36 dias. Segundo Brown et al. (1996), entre 10 a 14 dias antes do término da incubação, o mau posicionamento e edema são os principais achados, $55 \%$ e $41 \%$, respectivamente.

A presente pesquisa sugere que ambos os princípios ativos podem ser utilizados para uma eficiente desinfecção dos ovos, entretanto direciona futuras pesquisas referentes a outros manejos da incubação e sanidade das aves reprodutoras do plantel. Dessa forma, novas pesquisas devem ser conduzidas visando aumentar a taxa de nascimento e sobrevivência dos filhotes.

\section{Conclusão}

Tanto formaldeído como amônia quaternária são eficientes na desinfecção dos ovos de avestruzes, controlando agentes microbianos durante os processos de armazenagem e incubação além de não influenciarem os parâmetros da incubação. Porém, aconselha-se que para uso diário, seja utilizado a amônia quaternária ao invés do formaldeído, uma vez que a utilização de formaldeído pode ser tóxica.

\section{Referências}

BRAKE, J.; SHELDON, B. W. Effect of a quaternary ammonium sanitizer for hatching eggs on their contamination, permeability, water loss, and hatchability. Poultryscience, v. 69 , n. 4, p. 517525, $1990 . \quad$ Disponível em: http://ps.oxfordjournals.org/content/69/4/517.s hort. Acesso em: 10 mar. 2016. https://doi.org/10.3382/ps.0690517

BRAMWELL, R. K. Egg shell mottling and hatchability. The Poultry Site. 2002. Disponível em:

http://www.thepoultrysite.com/FeaturedArticle/ FATopic.asp?AREA=Incubation\&Display=28.

Acesso em: 06 fev. 2016.

BROWN, C. R.; PEINKE, D.; LOVERIDGE, A. Mortality in near-term ostrich embryos during artificial incubation. British Poultry Science, v.37, p.73-85, 1996. Disponível em: 
https://www.tandfonline.com/doi/abs/10.1080/0 0071669608417838. Acesso em: 5 mai. 2016.

CARRER, C. C.; KORNFELD, M. E. Taxa de fertilidade e índice de perda de peso de ovos de avestruzes (Struthiocamelus), sob incubação artificial. In: Congresso Brasileiro de Estrutiocultura, 2001. Campinas. Anais [...]. Campinas: Associação de Criadores de Avestruzes do Brasil, 2001. 1CD-ROM.

CARRER, C. C. et al. A criação do avestruz: guia completo de $A$ a Z. 1. ed. Pirassununga: Brasil Ostrich, 2004.

CONY, H. C. Métodos de desinfecção e princípios ativos desinfetantes e a contaminação, mortalidade embrionária e eclodibilidade de ovos e embriões de aves. 2007. $101 \mathrm{f}$. Dissertação (Mestrado em Zootecnia) Universidade Federal do Rio Grande do Sul, Porto Alegre, RS, 2007. Disponível em: http://www.lume.ufrgs.br/handle/10183/11260.

Acesso em: 14 mar. 2018.

DEEMING, D. C. Factors affecting hatchability during commercial incubation of ostrich (Struthiocamelus) eggs. Brithish Poutry Science, v.36, p.51-65, 1995. Disponível em: https://www.ncbi.nlm.nih.gov/pubmed/7614026. Acessoem: 25 fev. 2018. https://doi.org/10.1080/00071669508417752

GONZALEZ, A. et al. Factors affecting ostrich egg hatchability. Poultry Science, v.78, n. 9, p.12571262, $1999 . \quad$ Disponível em: https://www.ncbi.nlm.nih.gov/pubmed/1051535 4. Acesso em: 10 abr. 2018. https://doi.org/10.1093/ps/78.9.1257

HICKS-ALLDREDGE, K. Ratite reproduction. Veterinary Clinics of North America: Food Animal Practice, v. 14, n. 3, p. 437-453, 1998. https://doi.org/10.1016/S07490720(15)30230-9

LACERDA, M. J. R. et al. Physical and microbiological quality of opaque, sanitized, and chilled quail eggs experimentally contaminated with Salmonella enteric ser. Typhimurium. Ciência Animal Brasileira, v. 17, n.1, p.11-25, 2016. Disponível em: http://www.scielo.br/pdf/cab/v17n1/1809-6891- cab-17-01-0011.pdf>. Acesso em: 15 abr. 2018. https://doi.org/10.1590/1089-6891v17i118546

LACERDA, M. J. R. Sanitização e refrigeração de ovos de codornas comerciais contaminados experimentalmente por Salmonella Typhimurium. 2011. 86 f. Dissertação (Mestrado em Ciência Animal) - Escola de Medicina Veterinária e Zootecnia, Universidade Federal de Goiás, Goiânia, 2011.

NAHM, K. H. Effects of storage length and weight loss during incubation on hatchability of ostrich eggs (Struthiocamelus). Poultry Science, v.88, p.1667-1670, 2001. Disponível em: https://watermark.silverchair.com/poultrysci801667.pdf?t8ZNp-IIGDpF. Acesso em: 25 jul. 2017. https://doi.org/10.1093/ps/80.12.1667

OLIVEIRA, M. W. M. et al. Uso alternativo de incubadoras horizontais na incubação de ovos de avestruz. ANAP, v.10, n.1, p. 1-12, 2014. Disponível em: http://amigosdanatureza.org.br/publicacoes/ind ex.php/forum ambiental/article/view/781.

Acesso em: 05 fev. 2016. https://doi.org/10.17271/198008271012014781

SCOTT, T. A.; SWETNAM, C. Screening sanitizing agents and methods of application for hatching eggs I. Environmental and user friendliness. The Journal of Applied Poultry Research, v. 2, n. 1, p.1-6, 1993. Disponível em: https://doi.org/10.1093/japr/2.1.1

STRINGHINI, M. L. F. Perfil socioeconômico e microbiológico de manipuladores e qualidade de ovos de granjas de produção comercial. Influência da contaminação experimental por Pseudomonas aeruginosa sobre a qualidade de ovos não-lavados e lavados. 2008. 142 f. Tese (Doutorado em Ciência Animal) - Faculdade de Medicina Veterinária, Universidade Federal de Goiás, Goiânia, 2008.

VAN SCHALKWYK, S. J. et al. Repeatability and phenotypic correlations for body weight and reproduction in commercial ostrich breeding pairs. British Poultry Science, v. 37, n. 5, p. 953962, 1996. Disponível em: https://www.tandfonline.com/doi/abs/10.1080/0 0071669608417926. Acesso em: 04 mar. 2018. https://doi.org/10.1080/00071669608417926 